\title{
TRIBUNA LIBRE
}

\author{
F. Priero, $\mathbb{S}_{*} w_{x}$
}

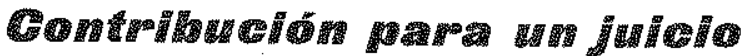 6์tico

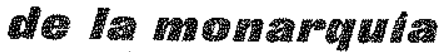

\begin{abstract}
En enero, las declaraciones del príncipe D. Juan Carlos removieron el sólito sosiego del panorama político español al inyectar una dosis de renovacła actualidad en el tema cumbre de la sucesión de la Jefatura del Estado. Y así como en los dos primeros años de la nueva etapa política que significa la Ley Orgánica del Estado me pareció adivinar en los medios de opinión pública un tenue predominio de la solución regencialista, ahora se lee y se oye decir que la cosa ya está hecha y que pronto Franco va a dar entrada en escena al artículo $6 .^{\circ}$ de la Ley de Sucesión que aguardaba pacientemente su turno entre bastidores desde el 26 de julio de 1947 :
\end{abstract}

En cualquier momento el Jefe del Estado podrá proponer a las Cortes la persona que estime deba ser llamada en su día a sucederle, a título de Rey o Regente...

Se entiende, claro está, que se trata de nombrar al sucesor a título de Rey.

\section{MONARQUIA. Y ENTUSIASMO}

La Jefatura monárquica lleva hoy consigo dos cualidades esenciales que la tipifican en el Derecho Político. Primera, en cuanto a la duración del cargo: vitalicia. Segunda, en cuanto al modo de designación de la persona: hereditaria. En nuestro caso, y puesto que se trata de instauración, muchos se inclinan a que no cuenta para nada la segunda, y aquí está la disyuntiva entre padre o hijo de todos conocida.

Es evidente que la mentalidad política de las gentes del siglo $\mathrm{xx}$ ha ido evolucionando en el sentido de no admitir la monarquía como forma de gobierno. Es evidente porque los nuevos estados que a la vida vienen nunca piensan en buscarse un rey para su jefatura y algunos de los antiguos se pasan de vez en cuando a la forma republicana. Se pasó Portugal, se pasó Turquía..., se pasó Italia..., se pasó Iraq. Además, parece que la institución monárquica sigue en pie en unos pocos paises más por inercia 
histórica --que también es una razón de peso a la hora de formar un juicio y de tomar una decisión ética-..- que por fervores monárquicos: en Suecia se plantea en el Pariamento la posibilidad de una transiormación de la forma de gobierno, y, que yo sepa, nadie se ha asustado; en Inglaterra parte de la juventud siente poco entusiasmo por su mítica casa real (inconcecible hace veinte años!); iy qué habrá que decir a la juventud españota, entendiendo por tal a los que somos de cuarenta años para abajo y que, además, somos la gran mayoría de la población?

Se me ocurre que este alejamiento general de la forma monárquica se produce no ponque los reyes sean malos o ineptos o crue'es o etc., sino precisamente por aquellas dos cualidades que son el santo y seña de la monatquía. Hoy no gusta el cargo vitalicio porque se piensa que frema la adecuada renovación de las instituciones y estructura de la sociedad, y hasta los obispos, que tienen a su favor sobre los monarcas la gracia de un sacramento, son gentimente invitados a renunciar a su tarea "cuando por edad avanzada, o por otra causa grave, se hacen menos aptos para el cumplimiento de su cargo" (Concilio Vaticano II, Decreto sobre el minis. terio pastoral de los obispos, núm. 21). Hoy tampoco gusta lo de "hijo de papá" como razón para lograr posición o fortuna en la sociedad; gusta por el contrario el principio de igualdad de oportunidades. Y si todavía el principio es poco operativo en la esfera de lo privado, aicanza ya categoría constitucional en la esfera de lo público (por ejemplo el artículo 11 del Fuero de los Españoles): Hasta aquí el enfriamiento de los entusiasmos monárquicos.

Claro que la monarquía tiene también sus defensores, puesto que ahí están los monárquicos. Algunos la defienden por personalísimos intereses - fortuna y honra-, aunque asi de claro no lo dirán nunca. Pero no todos, porque creo que hay monárquicos honrados y sinceros, que es decir monárquicos razonables. Razones hay en pro de la monarquía: la historia, la continuidad, etc. Pero no es mi propósito renovar ahora una discusión sobre las formas de gobierno. Quería tan sólo dar fe de unas tendencias.

\section{EL REY Y LAS INSTITUCIONES}

Eso sí, con el paso de los siglos la monarquía ha venido sufriendo en la realidad y en la mentalidad de la gente una debiitación general de sus funciones. Nadie defiende hoy en serio to que seriamente se defendía en el siglo xvi: el monarca absoluto, vitalicio y hereditario. Por razones vam rias, incluido el bien mismo del monarca, sus facultades políticas han sido recortadas, bien por preceptos vinculantes de la Constitución escrita, bien por costumbres constitucionales igualmente vinculantes, es decir, por la realidad misma de las instituciones politicas. El encumbrado oficio de monarca ha quedado notablemente aliviado de tal manera que ya no hace falta un superdotado para llevarlo con garbo. Se piensa que un varón (las hembras casi no cuentan y, desde luego, no cuentan en España) de normales cualidades físicas y psíquicas, afiladas por una esmerada educación puede quedar a punto para el cargo. Así, pues, ya no hay monarcas a la in temperie: en las pocas monarquías que en el mundo quedan, el monarca vive abrigado por las instituciones formalizadas o no en la Constitución.

¿Y en España? ¿Qué es lo que pasa en España? También aqú vale el slogan: "España es diferente". Por un lado el próximo Jere de Estado se configura en la ley Orgánica con un cúmulo de amplísimas facu'tades. Se le nombra, es rerdad, un cuerpo consultivo - el Consejo del Reino-m 
y se le preceptúa su audiencia; pero casi nunca e' parecer del Consejo del Reino es vinculante (lo es, por ejemplo. en el caso en que el Jefe del Estado quiera destituir al jefe del Gobierno o a los otros altos cargos del Estado). Y téngase en cuenta que un tercio de los miembros del Consejo son nombrados directamente por el mismo Jefe del Estado. Por otro lado, tampoco la costumbre constitucional pone 'ímite $\mathrm{y}$ carril a la actividad del Jefe del Estado, sencillamente porque dicha costumbre no existe. Estoy seguro de que con el correr de los tiempos y sin necesidad de ulteriores formalizaciones - io cual no significan que no sean deseableslas instituciones politicas españolas irán tomando cuerpo y se impondrán usos que el juego político respetará. Pero el gran problema, quizá el angustioso problema del panorama político español es la falta de instituciones, instituciones maduras, cristalizadas, instituciones con barba y bigote. Al contrario, todas, quien más quien menos, están o estarán de estreno. El Gobierno todavía no anda solo, anda llevado de la mano de la fuerte personalidad de Franco. Claro que muchos españoles piensan que ahí ha estado el acierto. Pero el problema que aquí nos ocupa es lo que pa sará cuando esa mano suelte al Gobierno y le diga: "jEa!, comienza a andar por tu cuenta". También las Cortes tienen aspecto juvenil: se piensa en una reforma del Reglamento; es la primera legislatura que ha estrenado un nuevo sistema electoral con poco entusiasmo del pueblo, pero hay quien dice que las próximas elecciones sí irán en serio. La Justicia está esperando su Ley Orgánica. Y los Sindicatos la suya. Y el Movimiento acaba de empezar nueva vida. Y la Administración Local espera también su buena reforma con la elección democrática de los alca'des. Y la Prensa, el cuarto poder, parece que se inclina a que la tey actual es un traje demasiado ajustado y no le vendría mal ensanchar en algunos puntos, es decir, tampoco la Prensa ha llegado a su mayoría en cuanto a su quehacer político, sino que como a niña traviesa la Administración no le quita el ojo de encima, y de vez en cuando le da su pequeña o grande zurra. En conclusión, que si queremos un rey para próximo fefe de Estado, hemos de ser bien conscientes que tendremos un rey a la intemperie. Si sale mal la experiencia, no podremos consolarnos como Felipe II, cuando el fracaso de la Invencible: nosotros sí enviaríamos a nuestro rey a luchar contra los elementos. He aquí el primer prenotando para un juicio ético sobre el problema.

\section{LAS CUALIDADES DE UN MONARCA}

El artículo 9: de la Ley de Sucesión define los requisitos del futuro Jefe del Estado -rey o regente-. Algunos son muy concretos y no tienen especial relevancia para la finalidad de este ensayo: "ser varón..., jurar las leyes fundamentales". Pero la Ley tiene malicia, es decir, inteligencia y. oportunísimamente explícita el requisito clave: "poseer las cualidades necesarias para el desempeño de su alta misión". Cuando Franco o el Consejo de Regencia busquen al candidato que han de presentar a las Cortes, cuando los procuradores tengan que contestar aprobando o rechazando, ni legal ni éticamente pueden eludir el artículo 9 con su requisito clave. Lo cual supone dos cosas: primera, tener una clara idea de la altura de esa misión - me refiero a las dificultades, no at rango sociológicoy consecuentemente tener una idea sobre qué cualidades se necesitan para afrontarlo; segunda, examinar concienzudamente al candidato en cuestión a ver si cuenta en su haber con las cualidades requeridas.

Sobre lo primero, sobre los muy serios problemas con que se va a enfrentar el próximo Jefe de Estado por la carencia de instituciones con- 
solidadas ya he dicho bastante. Eso si, conviene ponderar que los problemas se crecen si la Jefatura del Estado se asigna vitaliciamente por aquello de que las personas se gastan con el uso.

Quiero añadir unas reflexiones sobre las cualidades. Han de estar, natura'mente, en proporción con la empresa. Si queremos tener un rey, hemos de preguntar: ihay entre los de estirpe real algún auténtico superhombre? Si así fuera, la decisión, en cuanto a su aspecto ético, estaba resuelta. Quedaría el problema sentimental o estético para quien no guste de las ceremonias de la Corte o para quien prefiera una igualdad de oportunidades que llegue hasta la cumbre. Pero la conciencia de los procuradores quedaría transparente de puro limpia si dijeran que sí al posible superhombre. Insisto en que el probiema se plantea con vistas al próximo Jefe de Estado. Pasando los años y con instituciones consolidadas las tareas son más fáciles y por ende la cualidades requeridas son más comunes. Esto mismo supone que para un regente por seis, ocho o diez años no es necesario buscar un superhombre; puede la nación permitirse el lujo de que haya sus fallos en la regencia: ya habrá ocasión de enmendarlos sin que el tiempo los agrande.

$\mathrm{Y}$ vamos con lo segundo: el examen del candidato. Legal y éticamente digo que mientras no me conste que D. Fulano posee "las cualidades necesarias para el desempeño de su alta misión", yo, si fuera procurador en Cortes, no puedo darle mi aprobación sea a título de rey o de regente. Hace faita una cierta exhibición previa de la musculatura política del candidato para saber si podrá con el cargo. Ahora bien, las cualidades se demuestran en la acción. Hoy sabemos todos los españoles de personalidades ilustres que se han acreditado como hombres de gobierno por la eficiencia de su gestión al frente de un Ministerio o de una Dirección General, y decimos: "Fulano es hombre de gobierno". Pero de personas de estirpe real sabemos poco. A lo más que llegamos es a los rumores: "Dicen que es muy inte'igente". Y ya es algo, pero no basta, porque la inteligencia es necesaria, pero ella sola no califica a un hombre como gobernante, que es lo que queremos. Quizá haya personas de estirpe real con cualidades eminentes, superlativas, para ser rey ahora con todas las consecuencias, pero no consta.

E1 l de octubre de 1936 cargaron a Franco con todo el poder y sin instituciones, peor aún, en medio de una guerra. Mucha carga, sin duda, pero a los miembros de la Junta de Defensa Nacional les constaba sus cualidades acreditadas por una brillante historia militar y de mando. Fue aquella una decisión éticamente correcta. Mi deseo con estas líneas es haber contribuido a que cuando llegue el momento de adjudicar la Jefatura al sucesor de Franco, tan seria decisión política sea también éticamente correcta. 